\title{
Feasibility study for implementation of sedimentation reduction measures in river harbours
}

\author{
H.J. Barneveld \\ HKV consultants, Lelystad, The Netherlands \\ J. Hugtenburg \\ Ministry of Transport, Public Works and Water Management, The Hague, The Netherlands
}

\begin{abstract}
Sedimentation in river harbours is a serious problem in the Netherlands. Costs for removal, transport, processing and storage of this (often contaminated) sediment are high. In addition sedimentation and dredging activities hinder inland navigation.

Harbours are often designed based on requirements imposed by safe and efficient navigation. In the past decades many (mainly desk and/or laboratory) studies have been carried out aiming at the reduction of harbour siltation rates. From these studies, it follows that reductions in siltation rates up to $50 \%$ may be reached. However, only few of such sedimentation reduction measures have been implemented. This study aims at exploring the possibilities to apply simple and effective siltation reduction measures in the harbours along the rivers in the Netherlands. From about 200 harbours along the River Rhine and River Meuse three harbours were selected. This selection was made in close consultation with experts and stakeholders, based on among others the siltation rate, harbour geometry from remote sensing images, flow velocities and representativeness for Dutch river harbours. One of the three harbours was further elaborated in a first design. As distinct from preceding studies the design for this pilot project has been made using field data and expertise of river managers and specialists, but without physical scale model studies and numerical experiments. In addition a simple cost benefit analysis has been carried out.

It is expected that this study will be continued with a detailed design of the selected measure. Ultimately this will lead to a prototype implementation in 2008. Such a pilot project combined with a sound monitoring program will show the feasibility of the followed approach. In addition it will provide valuable information on morphological impacts of a structural measure in prototype situations.
\end{abstract}

\section{INTRODUCTION}

\subsection{Background and social relevance of study}

Approximately nine million cubic meters of silt and sand is annually deposited in and along the main rivers in the Netherlands (River Rhine and River Meuse). Harbours and its entrances are notorious locations for such undesirable sedimentation. Removal, transport, processing and storage of this (often contaminated) material costs about M€120 every year, for which the Ministry of Transport, Public Works and Water Management is partly responsible.

The main consideration for harbour entrance design is nautical navigation. For an optimal nautical navigation, harbour entrances should be as wide as possible. This however also maximizes the volume of sedimentation in the harbour and its entrance. Intelligent design of harbour entrances, using state of the art hydraulic en morphologic knowledge can however lead to harbours that are both well accessible and less prone to sedimentation. This study aims to explore the possibilities to apply simple, robust and effective sedimentation reduction measures in existing and new harbours along rivers in the Netherlands.

\subsection{Previous studies, pilot projects and barriers for implementation}

In the past decades many (mainly desk and/or laboratory) studies have been carried out aiming at the reduction of harbour siltation rates. PIANC (2006) presents an overview. A prototype example is the application of a Current Deflecting Wall (CDW) in the tidal harbour Köhlfleethafen in Hamburg, Germany (Winterwerp, 2005). Despite of this successful example (a reduction of ca. $40 \%$ of the siltation rates), structures to reduce harbour sedimentation are not/hardly applied in the main river branches in the Netherlands. This is thought to be largely due to the inertia of the responsible water managers, thus preventing a possible paradigm shift to take place. This inertia is mainly 
based on a lack of experience with design, construction and efficacy of sedimentation reduction measures. This study (which is part of the programme Water INNovation source, WINN, supported by the Ministry of Transport, Public Works and Water Management) therefore aims at preparing and implementing a pilot project in order to gain experience with the effectiveness of sedimentation reduction measures in harbours along the rivers Rhine and Meuse.

\section{METHOD OF STUDY}

\subsection{Process followed}

First step in the project was to make an inventory of the relevant physical processes. First a literature survey on fluid dynamics, sediment load and morphology around harbour entrances was carried out. This included an assessment of the design parameters relevant for sediment exchange through the harbour entrance and sedimentation rates. In addition national and international experts were asked to fill in a questionnaire in this field. The results of the literature survey and expert consultation are found in Section 3.

In a second step river base data for harbours in the Netherlands were collected and a short list of possible pilot-locations was established.

Since the chances for a successful pilot project do not only depend on technical aspects, but also on practical and political aspects, two workshop sessions with water and harbour managers were organized as a third step. In these sessions a confrontation was made between technical data and practical aspects with regard to a possible implementation of measures. The first session, which was held in November 2006, led to the selection of three harbours of which a sedimentation reduction can be reached through an innovative harbour entrance design (adaptation of the entrance or sedimentation reduction measures). These harbours were: a recreational harbour in Roermond (along the river Meuse), the harbour of Haaften (river Rhine) and the harbour of the Amer electricity generating station (river Meuse). These harbours are described in Section 4.

Practical aspects eventually led to the harbour of the Amer electricity generating station to be the object of further study. In a second workshop session with experts and water managers, a sustainable measure for this harbour was selected to be elaborated further including a rough design and cost benefit analysis, which are described in Section 5.

\subsection{Data collection}

Within the relevant regional departments and three specialist services of the Ministry of Transport, Public

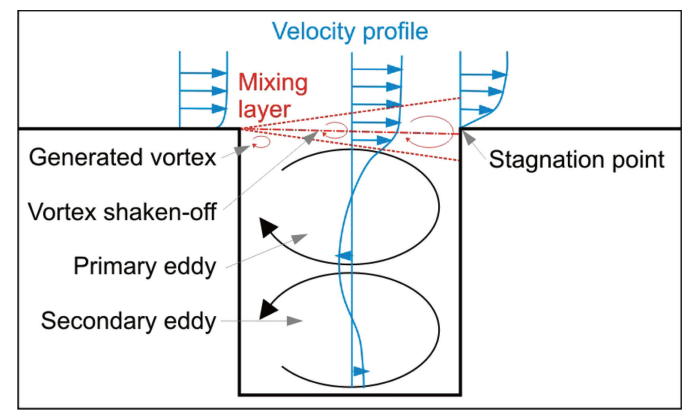

Figure 1. Horizontal entrainment mechanism.

Works and Water Management a questionnaire was distributed so as to collect data on:

1. dredging volumes in Dutch rivers, canals and harbours;

2. particular data for individual river harbours related to parties involved (ownership, stakeholders), geometry, sedimentation (rates, location, composition), causes of that, future plans for the harbour.

The collected data was combined with aerial photographs (Google Earth) to prepare a fact sheet per harbour. These fact sheets proved to be valuable in the preparation of a short list of potential harbours for the pilot.

\section{LITERATURE SURVEY}

\subsection{Fluid dynamics, sediment load and morphology around harbour entrances}

Possible mechanisms responsible for sedimentation are extensively reported in literature. Langendoen (1992), Winterwerp (2005) and PIANC (2006) provide an overview. Most important mechanisms are:

1. horizontal entrainment (turbulent mixing layer)

2. tidal filling

3. density currents

In river systems horizontal entrainment is the main mechanism, which is therefore considered in this paper (Figure 1).

According to van Schijndel and Kranenburg (1998) the sediment flux $\mathrm{F}$ through the harbour entrance can be described with:

$$
F=k u_{r}\left(c_{r}-c_{h}\right) A
$$

with:

$c_{r}=$ mean sediment concentration in river

$c_{h}=$ mean sediment concentration in harbour

$u_{r}=$ mean flow velocity river

$A=$ flow area harbour entrance

$k=$ exchange coefficient 
Equation (1) shows that the sediment flux will reduce linearly with smaller $c_{r}, u_{r}, A$ and $k$. The first two parameters are difficult to change, but influencing $\mathrm{A}$ and $\mathrm{k}$ appears to be feasible. As the vortexes in Figure 1 prove to be important for the magnitude of the exchange coefficient $k$, additional attention was paid to the generation, growth and diminishing of these structures. It appeared that the bigger and more intense a vortex is, the larger the sediment flux will be. The sediment flux can be reduced by:

1. suppressing the intensity and dimension of the vortexes that are shaken off at the upstream point of the entrance. This can be reached by reducing the flow velocity in the river (influencing the intensity of the vortex) or influencing the shape of the primary eddy (influencing the space left over by this eddy for generation of the vortex);

2. limiting the growth of the vortex in the mixing layer. Widening of the mixing layer may realise this;

3. transition of the stagnation point so as to guide more vortexes reaching the downstream point of the harbour entrance back to the river.

Measures to realise this are presented in the next paragraph.

\subsection{Harbour entrance designs effective for reduction of sedimentation}

Based on descriptions in literature eight possible measured were identified to:

1. reduce the shaking-off of vortexes;

2. reduce the flow area of the harbour entrance;

3. move the stagnation point;

4. reduce the sediment concentration of the water flowing into the harbour;

Figure 2 shows seven of the eight identified measures. Narrowing the entrance by construction of a bottom sill is not included in the Figure.

The current deflecting wall (CDW) reduces the shaking-off process of vortexes, diverts the entrainment mixing layer away from the entrance and prevents high concentrations near the bed from entering the harbour. A pile groyne widens the mixing layer and reduction of the flow velocity in the river. This suppresses the generation and growth of vortexes. A dividing wall with upstream sill at the upstream side of the harbour leads relatively clear water to the harbour and prevents water with high sediment concentrations from entering the harbour. Narrowing the entrance and construction of a sill to shallow the entrance both reduce the flow area of the harbour entrance, and thus the sediment flux. Adaptation of the harbour mouth downstream or upstream may shift the stagnation point respectively suppress the process of shaking-off of vortexes. A semi-permeable screen diverts the upper part of the water column towards the harbour. This

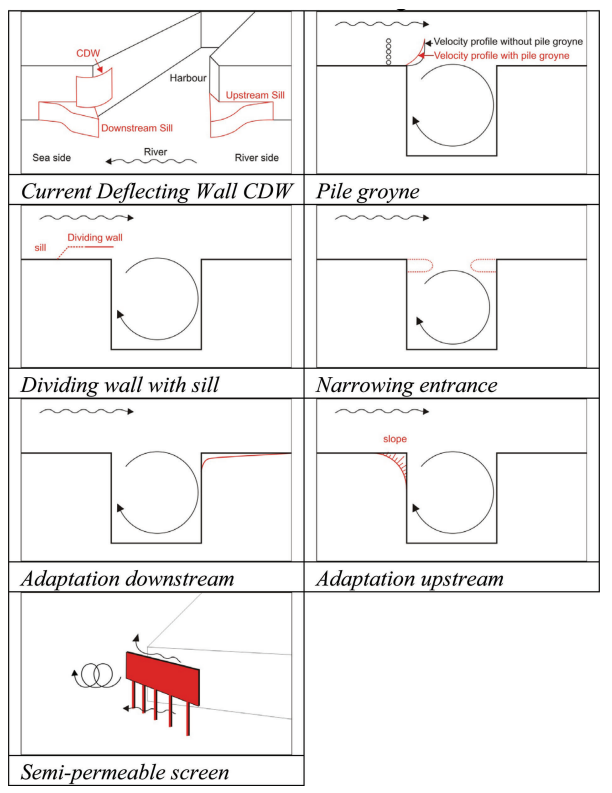

Figure 2. Measures to reduce the sediment flux.

Table 1. Measures and their influence.

\begin{tabular}{|c|c|c|c|c|}
\hline & $\begin{array}{l}\text { Reduce the } \\
\text { shaking-off } \\
\text { of vortexes }\end{array}$ & $\begin{array}{l}\text { Reduce } \\
\text { flow } \\
\text { area of } \\
\text { harbour } \\
\text { entrance }\end{array}$ & $\begin{array}{l}\text { Move the } \\
\text { stagnation } \\
\text { point }\end{array}$ & $\begin{array}{l}\text { Reduce } \\
\text { incoming } \\
\text { concentration }\end{array}$ \\
\hline CDW & $+?$ & & + & + \\
\hline Pile groyne & + & & + & \\
\hline $\begin{array}{l}\text { Dividing } \\
\text { wall \& sill }\end{array}$ & + & & & + \\
\hline $\begin{array}{l}\text { Narrowing } \\
\text { entrance }\end{array}$ & & + & & \\
\hline $\begin{array}{l}\text { Shallowing } \\
\text { entrance }\end{array}$ & & + & & \\
\hline $\begin{array}{l}\text { Adaptation } \\
\text { downstream }\end{array}$ & + & + & + & + \\
\hline $\begin{array}{l}\text { Adaptation } \\
\text { upstream }\end{array}$ & & + & + & \\
\hline $\begin{array}{l}\text { Semi- } \\
\text { permeable } \\
\text { screen }\end{array}$ & $+?$ & & & + \\
\hline
\end{tabular}

introduces a spiral motion leading the water near the bed (with most sediment) towards the river.

Table 1 presents the potency of these measures to influence the main mechanisms of sediment flux towards river harbours.

In addition the impacts of the measures for all riverine functions (navigation, safety, nature) were assessed.

The quantitative impact of a measure depends on local circumstances. The study aimed at designing a 


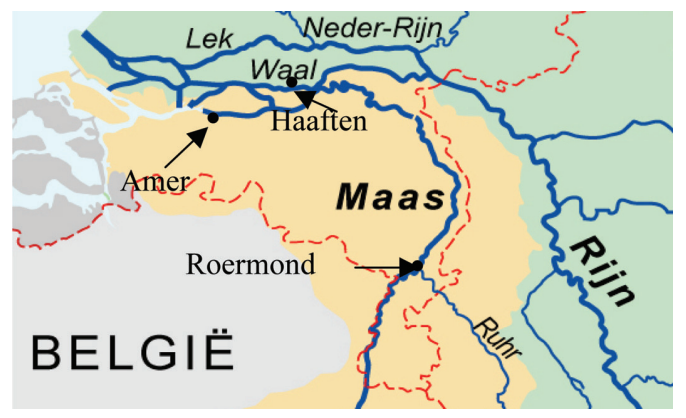

Figure 3. Location three harbours.

measure for a pilot harbour without extensive additional physical or mathematical modelling. Therefore also the possibility for quantifying the effect of the measures on the sedimentation process without additional study was assessed.

\section{POSSIBLE LOCATIONS FOR IMPLEMENTATION OF SEDIMENTATION REDUCTION MEASURES}

Figure 3 shows the location of three (out off appr. 200) selected harbours. This selection has been made in close consultation with experts and stakeholders based on among others the siltation rate, harbour geometry from remote sensing images, flow velocities and representativeness for Dutch river harbours.

\subsection{Recreation harbour of Roermond (river Meuse)}

The recreational harbour of Roermond in the river Meuse faces sedimentation problems since several years. Some studies have been executed showing that reduction of the entrance area would be a feasible solution. All stakeholders support a sustainable solution and the geometry of river and harbour appear to be representative for much more river harbours.

The municipality of Roermond recently approved a design by a consultant to realise this area reduction. Both the width and depth of the entrance will be reduced.

For this study this meant that an alternative design was not desirable. However, the implementation of the proposed measure may provide valuable information on the efficacy of it. Therefore a future activity concerning the design and implementation of a monitoring plan will be considered.

\subsection{Harbour of Haaften (Rhine)}

The harbour of Haaften serves as a resting harbour for inland navigation along the Rhine branch Waal. Apart from the sedimentation problem $\left(>3,000 \mathrm{~m}^{3}\right.$ annually)

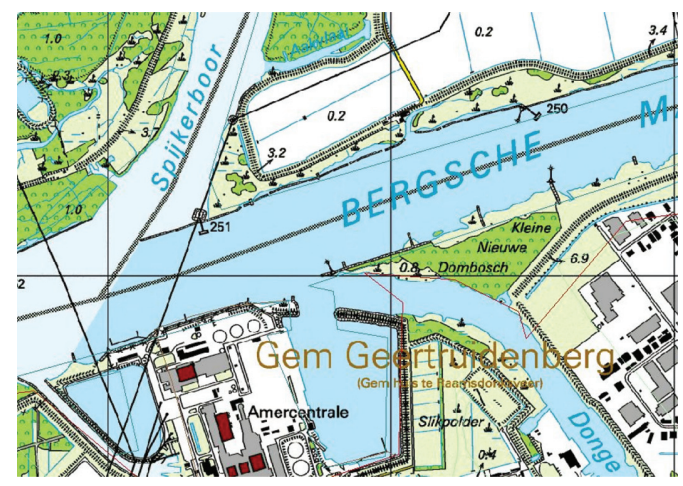

Figure 4. Harbour Amer electricity generating station (Amercentrale).

the harbour entrance causes problems for safe arrival in the harbour. This is especially the case during high water when the harbour entrance is submerged. Therefore studies are underway to adapt the harbour and entrance geometry so as to increase the capacity and make the harbour safer. Unfortunately data collection for this harbour faced delay, due to which no preliminary design for a sedimentation reduction measure could be preformed. However data collection will continue as a preparation for future studies for this harbour.

\subsection{Harbour of the Amer electricity generating station (Bergsche Meuse)}

The sedimentation in the mouth of this harbour is such, that on average a volume of $7,000-11,000 \mathrm{~m}^{3}$ of sand and (contaminated) silt is dredged annually. Both the management of the station and the river manager support a solution that can reduce the dredging costs and hindrance for navigation due to sedimentation and dredging works. In addition sufficient data is available to make a first design of a sedimentation reduction measure.

Although the harbour is located in a complex environment with different waterways meeting each other, and extraction of cooling-water (maximum $30 \mathrm{~m}^{3} / \mathrm{s}$ ) via the harbour, a pilot implementation for this harbour will provide valuable information on the performance of a measure and impacts on flow patterns. This pilot project is further elaborated in the next section.

\section{TOWARDS A SUSTAINABLE REDUCTION OF SEDIMENTATION IN THE AMER POWER STATION RIVER HARBOUR}

Aim of the study was to prepare a design for an adapted harbour geometry or a sedimentation reducing measure based on available field data, some 
exploring numerical flow simulations and engineering judgement. This means no extensive studies with physical scale models or numerical experiments. Most important result should be a pilot project and sound monitoring programme so as to learn in the field.

\subsection{Harbour and sedimentation characteristics}

The harbour area is about 17.5 ha large. The harbour entrance is $120 \mathrm{~m}$ wide and the opening between Bergsche Maas and Donge approximately $185 \mathrm{~m}$ wide. Main discharge comes through the Bergsche Maas with an average annual flow of about $300 \mathrm{~m}^{3} / \mathrm{s}$ and flood discharges of $1000 \mathrm{~m}^{3} / \mathrm{s}$ and higher. Discharge through the Donge is usually small (less than $3 \mathrm{~m}^{3} / \mathrm{s}$ ). The influence of the tide is still noticeable in the harbour, but reverse (upstream) flow is rare.

At two locations cooling-water for the power station is withdrawn. These locations are at the Bergsche Maas and in the harbour (both maximum $30 \mathrm{~m}^{3} / \mathrm{s}$ ). Especially in the winter season (September-March) full cooling-water capacity is used. Figure 5 shows a calculated flow pattern with a mean discharge Bergsche Maas of $300 \mathrm{~m}^{3} / \mathrm{s}$ and a cooling-water withdrawal of $30 \mathrm{~m}^{3} / \mathrm{s}$.

Sedimentation in the area of the harbour, its entrance, the river and the mouth of the Donge is estimated to be $12,500-21,000 \mathrm{~m}^{3}$ per year. About $7,000-11,000 \mathrm{~m}^{3}$ of this is found in the area of the harbour entrance and Donge mouth. $50 \%$ of this material is (contaminated) silt. This means that all dredged material has to be disposed at special sites.

Most sedimentation occurs during the high water season (October-March) when river discharges and sediment concentrations are high.

\subsection{The proposed solution}

Based on the information available for the harbour six possible measures for a pilot project were identified. Of the 7 measures presented in Figure 2 the following measures were considered not-feasible:

- A Current Deflecting Wall was rejected because this measure certainly needs additional study in the complex situation of this harbour.

- Adaptation of the mouth/entrance upstream or downstream was considered not-feasible because of the local geometry and presence of infrastructure.

A sediment trap upstream of the harbour entrance was added as a possible measure.

In Table 2 the remaining measures are assessed on their expected efficiency for the situation with and without withdrawal of cooling-water through the harbour.

As the sedimentation process mainly takes place in the high-water season and cooling-water withdrawal is continuous then, only the diving wall with sill,

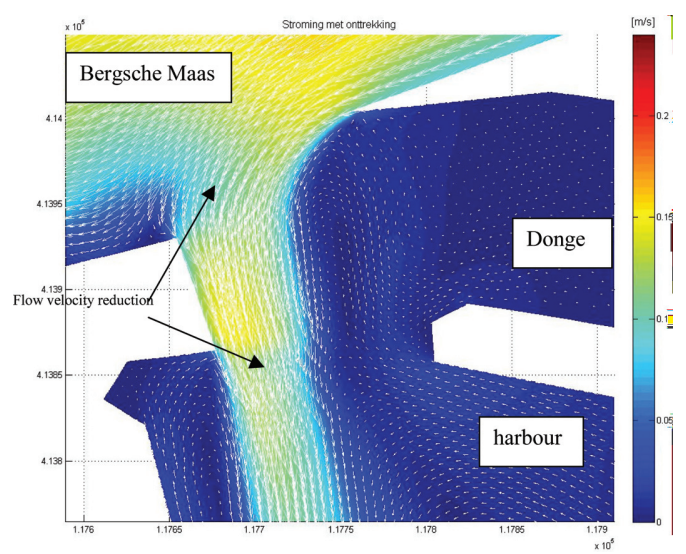

Figure 5. Flow pattern at $300 \mathrm{~m}^{3} / \mathrm{s}$ with $30 \mathrm{~m}^{3} / \mathrm{s}$ cooling-water withdrawal, calculated with FINEL.

Table 2. Assessment measures with and without coolingwater withdrawal.

\begin{tabular}{|c|c|c|}
\hline \multirow[b]{2}{*}{ Measure } & \multicolumn{2}{|c|}{$\begin{array}{l}\text { Cooling-water withdrawal } \\
\text { withdrawal }\end{array}$} \\
\hline & With & Without \\
\hline Pile groyne & $?$ & + \\
\hline Dividing wall \& sill & + & + \\
\hline Narrowing entrance & $?$ & + \\
\hline $\begin{array}{l}\text { Secondary channel through } \\
\text { upstream flood plain }\end{array}$ & + & + \\
\hline Semi-permeable screen & 0 & + \\
\hline $\begin{array}{l}\text { Sediment trap upstream } \\
\text { entrance }\end{array}$ & + & + \\
\hline
\end{tabular}

secondary channel through the upstream floodplain and the sediment trap upstream of the harbour entrance appear to be feasible. The first two measures aim at leading relatively clear water from the upper part of the water column to the harbour. The sediment trap prevents the sand fraction of the sediment load from entering the harbour. Taking into consideration that the proposed measure should be applicable for other river harbours the dividing wall with sill was selected for further elaboration.

Figure 6 shows a first design for this measure.

Based on experiences from the river manager and experts from specialist services and consultants a first estimate was made of the expected impact of the measure on the sedimentation rate. It is expected that the inflow of sand may be reduced by $50 \%$. This means that the total sedimentation rate (of sand and silt) will be reduced by $25 \%$.

When the measure is implemented a sound monitoring programme has to be implemented. This programme should record the existing situation and follow the developments after construction. 


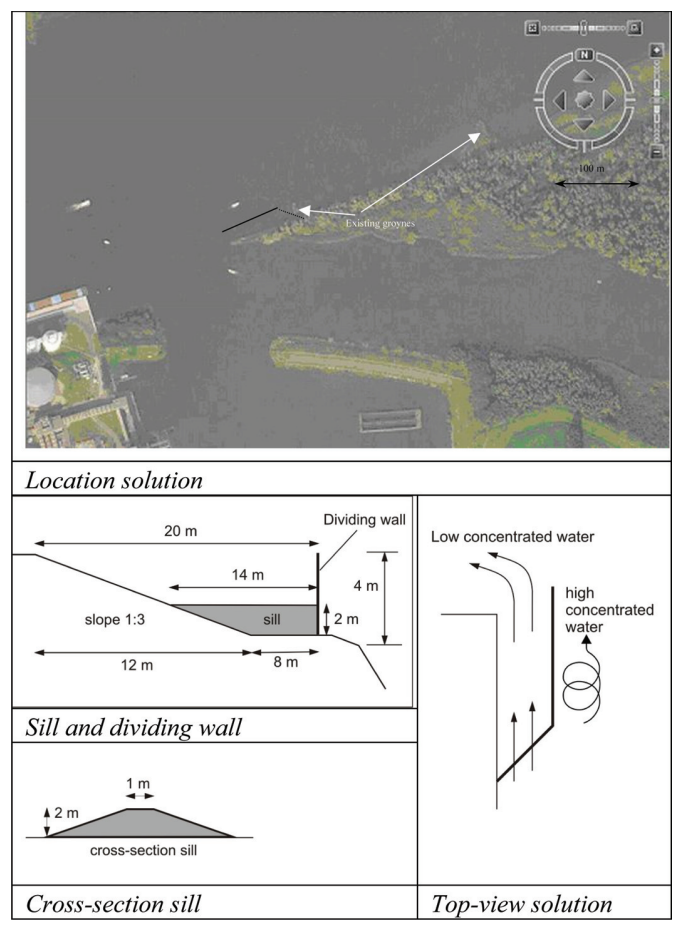

Figure 6. First design dividing wall and sill.

The monitoring programme will survey:

- Bed development. Coupled to the regular soundings some additional local measurements are foreseen after (1) floods, (2) dredging, (3) particular events (e.g. dredging in the main river);

- Flow patterns in river and harbour;

- Composition of the bed material in river, entrance and harbour.

\subsection{Rough cost benefit analysis}

Costs of the measure are related to (detailed) design, construction and maintenance. Benefits are the reduced dredging activities. Less hindrance for inland navigation is not taken into consideration for this analysis. Based on costs of $€ 5$ per $\mathrm{m}^{3}$ dredged material, $11,250 \mathrm{~m}^{3}$ reduction in the annual dredging volume, construction costs of $€ 250,000$, a discount-rate of $2.5 \%$ and a life-cycle period of 30 years the Net Present Value NPV (2007) for the average estimate is approximately $€-9.000$, meaning that the investments for the measure will not pay back completely in 30 years. For the optimistic estimate of $13,750 \mathrm{~m}^{3} / \mathrm{s}$ dredged volume reduction the NPV increases to $€+45,000$. However a pessimistic assumption (only $8,750 \mathrm{~m}^{3}$ reduction per year) will result in a NPV of $€-62,000$.

\section{DISCUSSION}

Objective of the study was to elaborate a first design of a sedimentation reduction measure in a Dutch river harbour. This should be achieved by a study based on field data and experiences of river managers and experts. Extensive physical scale modelling or numerical modelling did not form part of the study. When implementation of a measure designed in this way proves to be effective, this approach can be adopted for other locations. Intensive and specific monitoring is an important pillar of the approach that can be described with learning in the field.

It is proposed that parallel to the preparation of the studies some numerical experiments and perhaps a few simple physical scale model tests (e.g. flume study) will be carried out to further refine the design. In this period also the reference situation (existing situation) should be recorded as a first phase of the monitoring programme.

\section{ACKNOWLEDGEMENTS}

The study was carried out by three consultancy firms in close co-operation with experts from specialist services and regional divisions of the Ministry of Transport, Public Works and Water Management. The authors wish to thank the other members of the project team: Bram van Prooijen (Svašek hydraulics), Nico Struiksma (Struiksma River Engineering), Paul Termes (HKV CONSUltants), Maarten van der Wal (Road and Hydraulic Engineering Institute, Ministry of Transport, Public Works and Water Management) and Arjan Hijdra (Civil Engineering Division, Ministry of Transport, Public Works and Water Management).

\section{REFERENCES}

Langendoen E.J. (1992). 'Flow patterns and transport of dissolved matter in tidal harbors'. PhD thesis, Delft University of Technology.

PIANC (2006): Minimising Harbour Siltation. Report of International Navigation Association. PIANC Working Group 43 (draft).

Prooijen van B.C. (2004). 'Shallow mixing layers'. Thesis Delft Technical University.

Schijndel van \& Kranenburg (1998). Reducing the siltation of a river harbour. Journal of Hydraulic Research. Vol. 36, 1998, No.5.

Winterwerp J.C. (2005): Reducing Harbor Siltation. I: Methodology. Journal of Waterway, Port, Coastal, and Ocean Engineering, Volume 131, Issue 6, pp. 258-266 (November/December 2005). 